\title{
Clinical Effects of Liraglutide in a Real-World Setting in Spain: eDiabetes-Monitor SEEN Diabetes Mellitus Working Group Study
}

\author{
Pedro Mezquita-Raya • Rebeca Reyes-Garcia • Oscar Moreno-Perez • \\ Javier Escalada-San Martin · Miquel Ángel Rubio Herrera · \\ Martin Lopez de la Torre Casares
}

To view enhanced content go to www.diabetestherapy-open.com

Received: April 16, 2015 / Published online: June 9, 2015

(C) The Author(s) 2015. This article is published with open access at Springerlink.com

\section{ABSTRACT}

Introduction: A limitation with randomized controlled trials is that, while they provide unbiased evidence of the efficacy of interventions, they do so under unreal conditions and in a very limited and highly

Part of the Diabetes Mellitus Working Group (DMWG) of the Spanish Society of Endocrinology and Nutrition (SEEN).

Electronic supplementary material The online version of this article (doi:10.1007/s13300-015-0112-4) contains supplementary material, which is available to authorized users.

P. Mezquita-Raya $(\bowtie)$

Unidad de Endocrinología, Nutrición y Riesgo

Vascular, Complejo Hospitalario Torrecárdenas,

Almería, Spain

e-mail: pmr.csp@gmail.com

P. Mezquita-Raya · R. Reyes-Garcia

Servicio de Endocrinología, Clínica San Pedro,

Almería, Spain

R. Reyes-Garcia

Unidad de Endocrinología, Hospital General

Universitario Rafael Méndez, Lorca, Murcia, Spain

e-mail: rebecarg@yahoo.com

O. Moreno-Perez

Sección de Endocrinología y Nutrición, Hospital

General Universitario de Alicante, FISABIO,

Universidad Miguel Hernández, Alicante, Spain selected patient population. Our aim was to provide data about the effectiveness of liraglutide treatment in a real-world and clinical practice setting.

Methods: In a retrospective and observational study, data from 753 patients with type 2 diabetes were recorded through an online tool (eDiabetes-Monitor).

Results: Mean baseline glycated hemoglobin $\left(\mathrm{HbA}_{1 \mathrm{c}}\right)$ was $8.4 \pm 1.4 \%$ and mean body mass index (BMI) was $38.6 \pm 5.4 \mathrm{~kg} / \mathrm{m}^{2}$. After 3-6 months of treatment with liraglutide, we observed a change in $\mathrm{HbA}_{1 \mathrm{c}}$ of $-1.1 \pm 1.2 \%$, $-4.6 \pm 5.3 \mathrm{~kg}$ in weight and $-1.7 \pm 2.0 \mathrm{~kg} / \mathrm{m}^{2}$

\section{J. Escalada-San Martin}

Departamento de Endocrinología y Nutrición, Clínica Universidad de Navarra, Pamplona, Spain

M. Ángel Rubio Herrera

Servicio de Endocrinología, Hospital Clínico San Carlos, Madrid, Spain

M. Lopez de la Torre Casares

Servicio de Endocrinología, Hospital Universitario Virgen de Las Nieves, Granada, Spain 
in BMI ( $p<0.001$ for all). Compared to baseline, there was a significant reduction in systolic blood pressure $(-5.9 \mathrm{mmHg}, \quad p<0.001)$, diastolic blood pressure $(-3.2 \mathrm{mmHg}$, $p<0.001)$, LDL cholesterol $(-0.189 \mathrm{mmol} / \mathrm{l}$, $p<0.001)$ and triglycerides $(-0.09 \mathrm{mmol} / \mathrm{l}$, $p=0.021)$. In patients switched from DPP-4 inhibitors, liraglutide induced a decrease of $-1.0 \%$ in $\mathrm{HbA}_{1 \mathrm{c}}(p<0.001)$ and a reduction in weight $(-4.5 \mathrm{~kg}, p<0.001)$. In patients treated with liraglutide as an add-on therapy to insulin a decrease of $-1.08 \%$ in $\mathrm{HbA}_{1 \mathrm{c}}(p<0.001)$ and a weight reduction of $-4.15 \mathrm{~kg}(p<0.001)$ were observed.

Conclusion: Our study confirms the effectiveness of liraglutide in a real-life and clinical practice setting.

Funding: Spanish Society of Endocrinology and Nutrition.

Keywords: Effectiveness; Liraglutide; Real life; Type 2 diabetes

\section{INTRODUCTION}

Liraglutide is a GLP-1 receptor agonist (GLP1RA) which induces a significant improvement in glycemic control, body weight and cardiovascular risk factors. Its use is costeffective when the clinical indicators and the total costs associated with type 2 diabetes mellitus (type $2 \mathrm{DM}$ ) management are analyzed [1]. Current recommendations prioritize the selection of antidiabetic treatments with low risk of hypoglycemia, and also recommend considering the effects of antidiabetic drugs on weight when selecting a treatment $[2,3]$. The presence of hypoglycemic events resulted in increased use of health-care resources [4], so the selection of antidiabetic treatment with a low risk of hypoglycemia may result not only in an improvement in the quality of life, but also in a reduction in costs [4]. Considering these findings, in a recent position paper from the Diabetes Mellitus Working Group of the Spanish Society of Endocrinology and Nutrition [5], the use of GLP1RA as a second- or third-line therapy is recommended in type $2 \mathrm{DM}$ patients with obesity due to its low risk of hypoglycemia and its additional effects beyond the improvement in glycated hemoglobin $\left(\mathrm{HbA}_{1 \mathrm{c}}\right)$ and weight.

The efficacy and safety of liraglutide both as mono- and combination therapy have been evaluated in the Liraglutide Effect and Action in Diabetes (LEAD) program, where liraglutide induced a decrease of $\mathrm{HbA}_{1 \mathrm{c}}$ between $0.8 \%$ and $1.5 \%$ [6-10]. In addition, liraglutide leads to a reduction in weight and also in blood pressure and lipids [11]. Due to its additional effects on glycemic control, liraglutide is associated with an improvement in life expectancy and in quality-adjusted life expectancy. It is also associated with a reduced cost in diabetes-related complications, so it is more cost-effective versus a DPP4 inhibitor [12].

A limitation with randomized controlled trials is that, while they provide unbiased evidence of the efficacy of interventions, they do so under artificial conditions and in a very limited and highly selected patient population. Consequently, there is uncertainty regarding whether the results obtained can be generalized to the diverse patient populations encountered in everyday clinical practice, and whether these results can be generalized to standard care. Reports about real-life effects of liraglutide have been published recently [13-17]. However, some of them have included a scarce number of patients treated with GLP1RA [1315]. Thus, the confirmation of these results in 
other countries and other populations is still necessary. In this study, we provide data about the effectiveness of liraglutide treatment in a real-life and clinical practice setting in Spain.

\section{METHODS}

This is a multicenter, retrospective and observational study. Data from type 2 DM patients were recorded through an online tool (eDiabetes-Monitor, available at www. diabetesmonitor.es) designed for recording data on clinical characteristics of type $2 \mathrm{DM}$ patients in clinical practice and for providing tools (as dietetic and exercise recommendations) for the management of these patients. Patients with type $2 \mathrm{DM}$, aged 18 years or older and treated with GLP1RA, were included. Exclusion criteria were type 1 diabetes and refusal to provide informed consent. Due to the retrospective design, the criteria for the selection of concomitant treatment, escalation of the dose of GLP1RA and maintenance of the dose were not specified in the study protocol and were done prior to the inclusion of the patients and according to routine clinical practice at the discretion of the investigator.

From June 2011 to February 2014, 753 patients treated with GLP1RA were included. In the year prior to the initiation of the study, only exenatide and liraglutide were available in Spain. Thus, the majority of the patients included in the study $(n=740)$ were treated with liraglutide and 13 patients treated with exenatide were excluded from the analysis. The main data from the study were $\mathrm{HbA}_{1 \mathrm{c}}$, weight and diabetes treatment before and after treatment with GLP1RA. Type 2 DM patients with at least two visits registered in the online tool (before the initiation of treatment and 3-6 months after that) and who had data about changes of $\mathrm{HbA}_{1 \mathrm{c}}$, weight or both were selected for analysis $(n=684)$. Patients in whom the treatment for blood pressure or lipids was modified were excluded. After that, 539 patients had complete data of changes in lipid profile and 520 patients had complete data regarding changes in blood pressure. Data on adverse events including symptomatic hypoglycemia or severe hypoglycemia were also collected.

The study was approved by the ethical review board of the centers which took part in the study and was done in compliance with the ethic guidelines for research in humans. All the procedures were in accordance with the ethical standards of the responsible committee on human experimentation (institutional and national) and with the Helsinki Declaration of 1964, as revised in 2013. All the participants in the study provided informed consent after a full explanation of the purpose of the study. Informed consent was obtained from all patients for being included in the study.

\section{Statistical analysis}

Data for continuous variables are presented as mean \pm standard deviation. Data for categorical variables are presented as numbers and/or percentages. Kolmogorov-Smirnov test was used to test the normality of distribution of continuous variables. Associations between continuous variables were described by Pearson's coefficients. Comparisons of categorical variables among groups were performed using Chi-square test. Comparisons of continuous variables among groups were performed using paired Student's $t$ test or ANOVA when two or more of groups were considered. Differences between variables before and after treatment were assessed by Student́s test for paired samples. The evaluation of variables influencing changes in $\mathrm{HbA}_{1 \mathrm{c}}$ and weight after liraglutide treatment was done by 
$t$ test when there were two conditions or by ANOVA when tertiles. The selection of variables was done according to clinical criteria and considering previous data from literature. A $p$ value of less than 0.05 was considered significant (two tailed). Data were recorded and analyzed using SPSS version 18.0 software (SPSS Inc, Chicago, IL, USA).

\section{RESULTS}

Baseline characteristics of type 2 DM patients before starting liraglutide are shown in Table 1. After the initiation of treatment with liraglutide $0.6 \mathrm{mg}$ and after the dose escalation, $26.5 \%$ of patients were treated with liraglutide $1.8 \mathrm{mg}$ and the remaining $73.5 \%$ with $1.2 \mathrm{mg}$. There

Table 1 Baseline characteristics of patients before starting liraglutide treatment

\begin{tabular}{|c|c|c|c|}
\hline & Number of patients & $\%$ & Mean \pm SD \\
\hline Age (years) & 738 & & $55.6 \pm 10.8$ \\
\hline Male/females (\%) & 740 & $50.5 / 49.5$ & \\
\hline Duration of diabetes (years) & 707 & & $10.0 \pm 6.3$ \\
\hline Previous treatment & 740 & & \\
\hline Metformin & & 87 & \\
\hline Sulfonylurea & & 20 & \\
\hline Repaglinide & & 3.8 & \\
\hline DPP4 Inhibitors & & 27.9 & \\
\hline Pioglitazone & & 5 & \\
\hline Insulin & & 27.2 & \\
\hline Basal insulin & & 18.8 & \\
\hline Number of OADs prior to liraglutide treatment & 740 & & \\
\hline 0 & & 10.1 & \\
\hline 1 & & 47.1 & \\
\hline 2 & & 28.3 & \\
\hline$\geq 3$ & & 14.5 & \\
\hline $\mathrm{HbA}_{1 \mathrm{c}}(\%)$ & 725 & & $8.4 \pm 1.4$ \\
\hline Weight $(\mathrm{kg})$ & 716 & & $104.7 \pm 19.3$ \\
\hline BMI $\left(\mathrm{kg} / \mathrm{m}^{2}\right)$ & 682 & & $38.6 \pm 5.4$ \\
\hline $\mathrm{SBP}(\mathrm{mmHg})$ & 637 & & $141.4 \pm 17.1$ \\
\hline $\mathrm{DBP}(\mathrm{mmHg})$ & 622 & & $83.1 \pm 11.1$ \\
\hline HDL cholesterol $(\mathrm{mmol} / \mathrm{l})$ & 647 & & $1.14 \pm 0.32$ \\
\hline LDL cholesterol $(\mathrm{mmol} / \mathrm{l})$ & 627 & & $2.70 \pm 0.84$ \\
\hline Triglycerides $(\mathrm{mmol} / \mathrm{l})$ & 676 & & $2.42 \pm 1.04$ \\
\hline
\end{tabular}

$B M I$ body mass index, $D B P$ diastolic blood pressure, $O A D s$ oral antidiabetic drugs, $H b A_{1 c}$ glycated hemoglobin, $S B P$ systolic blood pressure, $S D$ standard deviation 
were no differences in baseline $\mathrm{HbA}_{1 \mathrm{c}}(8.4 \%$ vs. $8.5 \%$ for liraglutide 1.2 and $1.8 \mathrm{mg}$, respectively, $p=0.430$ ) or baseline weight (105 vs. $102.6 \mathrm{~kg}$ for liraglutide 1.2 and $1.8 \mathrm{mg}$, respectively, $\quad p=0.172$ ). Likewise, no differences were found when analyzing changes in $\mathrm{HbA}_{1 \mathrm{c}}(-1.09 \%$ and $-1.05 \%$ for liraglutide 1.2 and $1.8 \mathrm{mg}$ respectively, $p=0.730)$ or weight $(-4.89 \mathrm{~kg}$ and $-4.5 \mathrm{~kg}$ for liraglutide 1.2 and $1.8 \mathrm{mg}$ respectively, $p=0.419)$ according to the dose of liraglutide.

After treatment with liraglutide, we observed a change in $\mathrm{HbA}_{1 \mathrm{c}}$ of $-1.1 \pm 1.2 \%$, $-4.6 \pm 5.3 \mathrm{~kg}$ in weight and $-1.7 \pm 2.0 \mathrm{~kg} / \mathrm{m}^{2}$ in body mass index (BMI) $(p<0.001$ for all). Liraglutide also induced a significant reduction in systolic blood pressure (SBP) $(-5.9 \pm 14.7 \mathrm{mmHg}, p<0.001)$, diastolic blood pressure (DBP) $(-3.2 \pm 10.7 \mathrm{mmHg}, p<0.001)$, LDL cholesterol $\quad(-0.189 \pm 0.802 \mathrm{mmol} / \mathrm{l}$, $p<0.001) \quad$ and triglycerides $\quad(-0.09 \pm$ $0.08 \mathrm{mmol} / \mathrm{l}, p=0.021$ ) (Table 2).

Eighty percent of patients achieved a reduction of $\mathrm{HbA}_{1 \mathrm{c}}$ and weight after liraglutide treatment. The correlation between changes in $\mathrm{HbA}_{1 \mathrm{c}}$ and changes in weight showed a weak relationship $(r=0.202, p<0.001)$. There were no differences in $\mathrm{HbA}_{1 \mathrm{c}}$ changes according to BMI categories. No differences in liraglutide effect (in terms of $\mathrm{HbA}_{1 \mathrm{c}}$ or change in weight) were found according to gender or diabetes duration (Fig. 1). However, the decrease of $\mathrm{HbA}_{1 \mathrm{c}}$ was higher in patients in the highest tertile of $\mathrm{HbA}_{1 \mathrm{c}}\left(\mathrm{HbA}_{1 \mathrm{c}} \geq 9.1 \%\right)$, and patients in the lowest tertile of age ( $\leq 50.8$ years) or in the highest tertile of BMI $\left(\geq 40.6 \mathrm{~kg} / \mathrm{m}^{2}\right)$ experienced a higher reduction in weight (Fig. 1). When analyzing liraglutide effects of weight according to baseline BMI, the reduction in weight was higher in patients with higher baseline BMI (Fig. 2).

The decrease in $\mathrm{HbA}_{1 \mathrm{c}}$ showed significant differences according to the oral antidiabetic drugs (OADs) added on to liraglutide (Fig. 3). The reduction in weight was highest $(-5.4 \mathrm{~kg})$ in patients treated with metformin and it was significantly higher compared to patients treated with secretagogues (sulfonylurea or

Table 2 Changes after liraglutide treatment

\begin{tabular}{llccc}
\hline & $\boldsymbol{N}$ & \multicolumn{1}{c}{ Before } & \multicolumn{1}{c}{ After } & \multicolumn{1}{c}{$\boldsymbol{p}$} \\
\hline $\mathrm{HbA}_{\mathrm{lc}}(\%)$ & 648 & $8.4 \pm 1.4$ & $7.3 \pm 1.3$ & $<0.001$ \\
Fasting glucose $(\mathrm{mmol} / \mathrm{l})$ & 597 & $10.00 \pm 3.26$ & $8.26 \pm 2.81$ & $<0.001$ \\
Weight $(\mathrm{kg})$ & 684 & $104.7 \pm 18.7$ & $100.1 \pm 18.2$ & $<0.001$ \\
$\mathrm{BMI}\left(\mathrm{kg} / \mathrm{m}^{2}\right)$ & 653 & $38.6 \pm 5.4$ & $36.9 \pm 5.3$ & $<0.001$ \\
SBP $(\mathrm{mmHg})$ & 520 & $140.0 \pm 16.6$ & $134.1 \pm 15.2$ & $<0.001$ \\
DBP $(\mathrm{mmHg})$ & 508 & $82.5 \pm 10.8$ & $79.3 \pm 9.5$ & $<0.001$ \\
HDL cholesterol $(\mathrm{mmol} / \mathrm{l})$ & 527 & $1.15 \pm 0.32$ & $1.13 \pm 0.31$ & 0.312 \\
LDL cholesterol $(\mathrm{mmol} / \mathrm{l})$ & 512 & $2.71 \pm 0.86$ & $2.53 \pm 0.76$ & $<0.001$ \\
Triglycerides $(\mathrm{mmol} / \mathrm{l})$ & 539 & $2.10 \pm 1.04$ & $2.01 \pm 1.04$ & 0.021 \\
\hline
\end{tabular}

Results expressed as mean \pm standard deviation

After excluding patients in whom the treatment for blood pressure or lipids was modified, 539 patients had complete data of changes in lipid profile and 520 patients had complete data regarding changes in blood pressure

$B M I$ body mass index, $D B P$ diastolic blood pressure, $H b A_{1 c}$ glycated hemoglobin, $S B P$ systolic blood pressure 

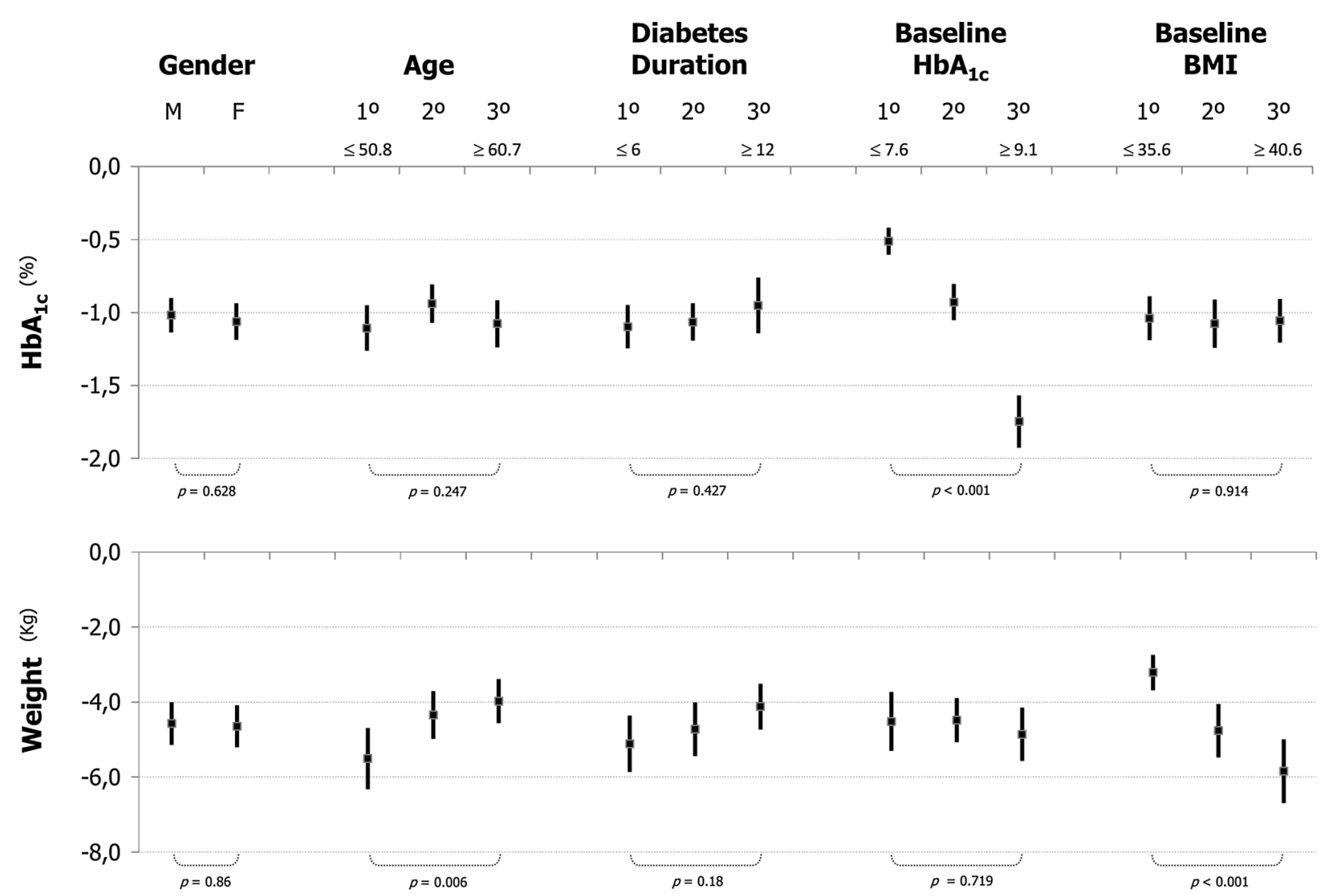

Fig. 1 Changes in $\mathrm{HbA}_{1 \mathrm{c}}$ and weight after liraglutide treatment in different subgroups of patients. Data are mean (point) and 95\% confidence interval. Age and diabetes duration is in years. $1^{\circ} 1$ st tertile (below: tertile's upper limit), $2^{\circ}$ 2nd tertile, $3^{\circ}$ 3rd tertile (below: tertile's lower

glinide) or secretagogues plus metformin (Fig. 3). The percentage of patients reaching a composite end point $\left(\mathrm{HbA}_{1 \mathrm{c}}<7 \%\right.$ and a decrease in weight without hypoglycemia) after liraglutide treatment was significantly higher in patients treated with metformin and liraglutide $(54.8 \%)$ compared to patients with added liraglutide to metformin plus secretagogues $(26 \%)$, or patients treated with liraglutide in combination with metformin plus basal insulin (24.2\%) $(p<0.05)$ (Fig. 3). In patients treated with liraglutide as monotherapy, a reduction of $-0.87 \%$ in $\mathrm{HbA}_{1 \mathrm{c}}$ and a decrease of $-4.46 \mathrm{~kg}$ was observed. limit), $B M I$ body mass index $\left(\mathrm{kg} / \mathrm{m}^{2}\right), F$ female, $H b A_{1 c}$ glycated hemoglobin, $M$ male. $p$ values are shown for $t$ test when there were two conditions or for ANOVA when tertiles

When we analyzed composite end points after liraglutide treatment, $48.3 \%$ of patients achieved an $\mathrm{HbA}_{1 \mathrm{c}}$ of $7 \%$ or less, $59.4 \%$ reached a weight reduction higher than $3 \%$ and in $28.1 \%$ both parameters were achieved (Fig. 4). Besides, in $36.3 \%$ of patients the reduction in weight was higher than $5 \%$, and $9.2 \%$ of patients lost more than $10 \%$ of their initial weight. We also observed an improvement in the control of blood pressure and LDL cholesterol. In addition, $27.7 \%$ of patients reached an end point of controlled SBP and DBP and LDL $<2.59 \mathrm{mmol} / \mathrm{l}$ (Fig. 4).

In patients previously treated with DPP-4 inhibitors, liraglutide in combination with 

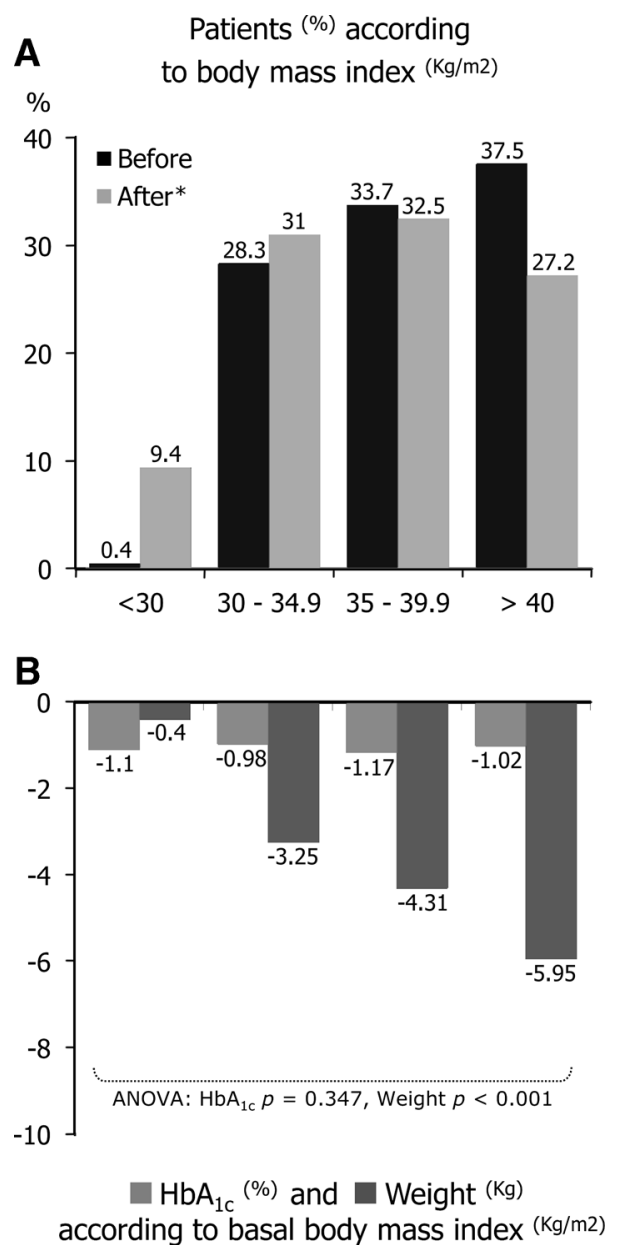

Fig. 2 Percentage of patients and changes in HbAlc and weight across baseline body mass index categories after liraglutide treatment. $H b A_{1 c}$ glycated hemoglobin. ${ }^{*} p<0.001$ (Chi-square test)

OADs decreased $\mathrm{HbA}_{1 \mathrm{c}}$ by $1.0 \%(p<0.001)$ and also induced a reduction of $-4.5 \mathrm{~kg}(p<0.001)$ (Fig. 5). In patients in whom DPP4 inhibitors were maintained after the initiation of liraglutide, $\mathrm{HbA}_{1 \mathrm{c}}$ decreased $-1.28 \%$ and the weight reduction was $-5 \mathrm{~kg}$. However, there were no significant differences in the reduction of $\mathrm{HbA}_{1 \mathrm{c}}$ when DPP-4 inhibitors were switched off or maintained. In patients treated with insulin \pm OADs, after add-on of liraglutide a reduction of $-1.08 \%$ in $\mathrm{HbA}_{1 \mathrm{c}}$ and $-4.15 \mathrm{~kg}$ was observed $(p<0.001$ for both) (Fig. 5). The change in $\mathrm{HbA}_{1 \mathrm{c}}$ and weight was higher when insulin and liraglutide were added to previous treatment $\left(\mathrm{HbA}_{1 \mathrm{c}}-1.43 \%\right.$, weight $\left.-7 \mathrm{~kg}\right)$ compared to switching from insulin to liraglutide \pm OADs $\quad\left(\mathrm{HbA}_{1 \mathrm{c}} \quad-0.68 \%\right.$, weight $-4.26 \mathrm{~kg}$ ) (Fig. 5).

Regarding adverse effects, clinically significant gastrointestinal symptoms were recorded in seven patients. Only one patient discontinued the treatment, and the other six patients remained on treatment with a slower dose escalation. However, 68 patients (10\%) who started liraglutide did not complete the two visits. We have no data regarding the reason for discontinuation, and we are aware that in many of these patients the reason may have been side effects, which will result in a similar percentage of side effects as have been reported in clinical trials. Hypoglycemic events were reported in $7.8 \%$ of patients. None of them were severe hypoglycemia. Hypoglycemic events were reported in $10.6 \%$ of patients treated with insulin and liraglutide, compared to $15.2 \%$ of patients treated with secretagogues and liraglutide $(p=0.369)$. In patients treated with liraglutide and metformin, the frequency of hypoglycemia was lower (1.6\%) compared to patients treated with insulin or secretagogues $(p<0.001$ for both).

\section{DISCUSSION}

This study confirms the effectiveness of treatment with liraglutide in Spanish type 2 DM patients in a real-world setting. These data demonstrated a $-1.1 \%$ mean reduction in $\mathrm{HbA}_{1 \mathrm{c}}$ and a decrease of $-4.6 \mathrm{~kg}$ in weight. Treatment with liraglutide allows many patients to reach composite end points, with $\mathrm{HbA}_{1 \mathrm{c}}$ of less than $7 \%$ and a weight reduction higher than $3 \%$. This was observed in $28.1 \%$ of patients after liraglutide treatment. 


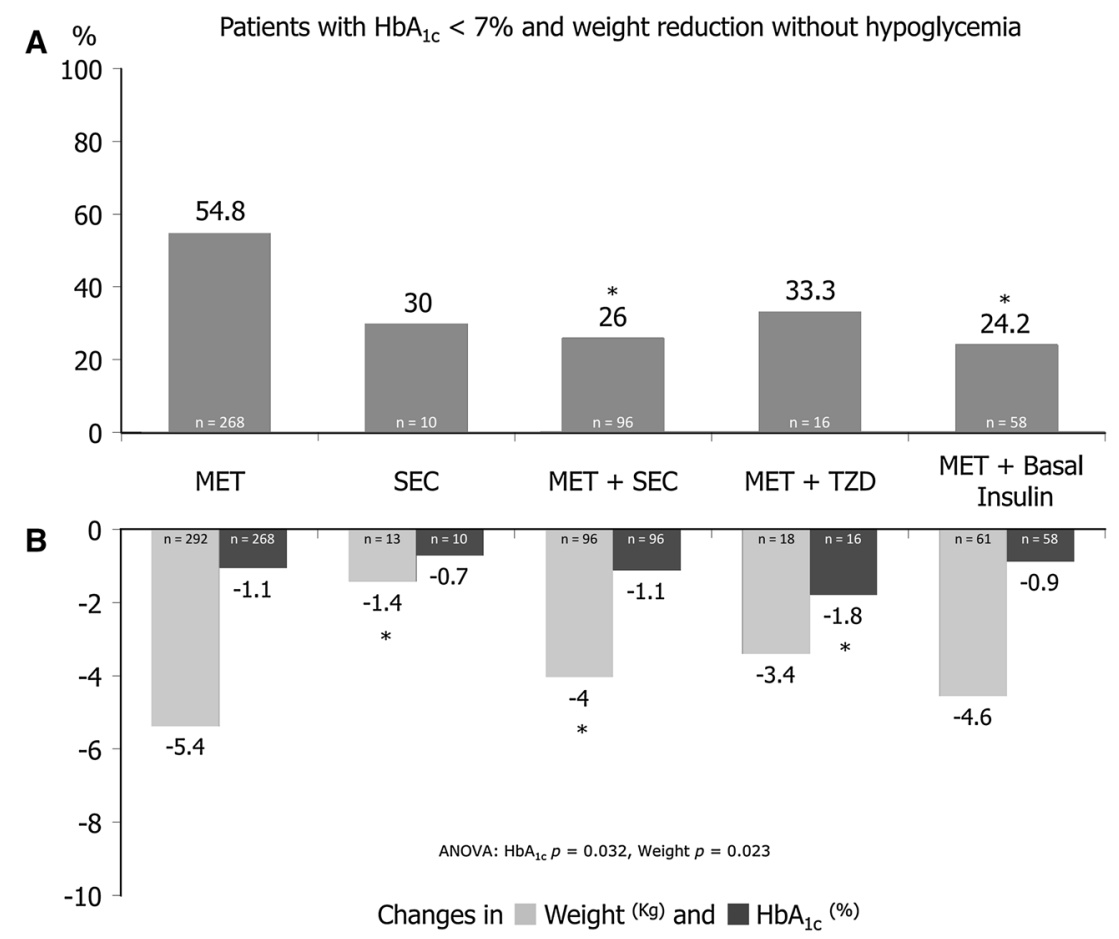

Fig. 3 Percentage of patients achieving glycemic control and weight reduction without hypoglycemia and changes in $\mathrm{HbA}_{1 \mathrm{c}}$ and weight according to the oral antidiabetic treatment associated with liraglutide. $H b A_{l c}$ glycated hemoglobin, $M E T$ metformin, SEC secretagogue

The reduction in $\mathrm{HbA}_{1 \mathrm{c}}$ in our study was somewhat lower than the effect reported in the LEAD trials, which may be explained by a longer duration of the disease (10 \pm 6 years) in the present study, compared to 7.7 years in LEAD studies. However, when analyzing real-life studies, the results of the present study are in line with previous data $[13,14]$ showing a reduction in $\mathrm{HbA}_{1 \mathrm{c}}$ between $-1.23 \%$ and $-1.5 \%$, and a mean weight reduction between -2.9 and $-4 \mathrm{~kg}$. We did not find differences in $\mathrm{HbA}_{1 \mathrm{c}}$ or weight changes according to the dose of liraglutide, which is in contrast to previous results from LEAD trials $[6,8]$. The presence of uncontrolled variables may have influenced these results, so no definite conclusions regarding the dose can be inferred from our data.

In the LEAD program, weight changes were between -1.38 and $-3.75 \mathrm{~kg}$ [6-10]. The mean (sulfonylurea or repaglinide), $T Z D$ thiazolidinedione. To $P$ a: ${ }^{*} p<0.05$ ( $Z$ test $)$ vs. metformin monotherapy. Below $\mathbf{b}$ : ${ }^{*} p<0.05$ ( $t$ test $)$ vs. metformin monotherapy

weight reduction in this study was higher $(-4.6 \mathrm{~kg})$ which may be explained by higher mean weight compared to LEAD studies. However, these results confirm previous retrospective data from the USA [17], where a reduction in weight between 1.5 and $4 \mathrm{~kg}$ and a decrease of $\mathrm{HbA}_{1 \mathrm{c}}$ between 0.95 and $1.02 \%$ were observed.

We did not find differences in $\mathrm{HbA}_{1 \mathrm{c}}$ reduction according to diabetes duration or the number of OADs. However, after treatment with liraglutide as monotherapy, the reduction in $\mathrm{HbA}_{1 \mathrm{c}}$ and weight was in line with results from LEAD 3 study, where liraglutide monotherapy for 2 years provided significant effect on glycemic control and body weight compared with glimepiride monotherapy, at a lower risk of hypoglycemia [18]. In addition, in our study changes in BMI after liraglutide were 


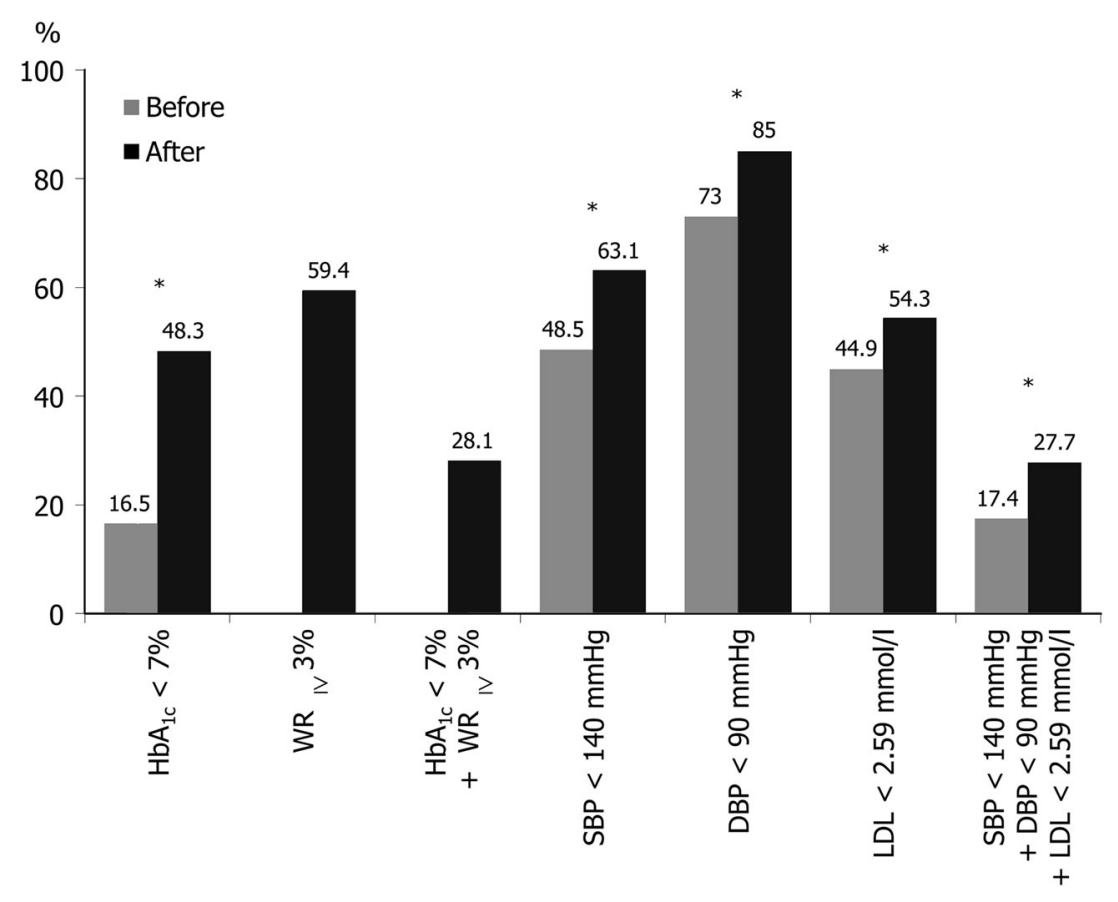

Fig. 4 Percentage of patients achieving glycemic control, weight reduction and control of cardiovascular risk factors after treatment with liraglutide. DBP diastolic blood pressure, $H b A_{1 c}$ glycated hemoglobin, $S B P$ systolic blood

higher in patients treated with metformin, and the percentage of patients reaching the composite end point of decreased $\mathrm{HbA}_{1 \mathrm{c}}$ and weight without hypoglycemia was highest in patients treated with metformin. This may indicate some benefits of an early initiation of liraglutide. However, the absence of drugs inducing weight gain, as the secretagogues, may have influenced these results. Moreover, the weak correlation between $\mathrm{HbA}_{1 \mathrm{c}}$ changes and weight reduction and the absence of differences in $\mathrm{HbA}_{1 \mathrm{c}}$ reduction according to previous OADs are of clinical relevance. Thus, even in the case of limited $\mathrm{HbA}_{1 \mathrm{c}}$ effectiveness, a clinically significant reduction in weight and consequently in diabetes-related complications risk may be expected.

In the present study after liraglutide treatment, a significant increase in the percentage of patients reaching a composite pressure, $W R$ weight reduction. ${ }^{*} p<0.001$ for the comparison between baseline and after treatment (Chi-square test)

end point of controlled SBP, DBP and LDL below $2.59 \mathrm{mmol} / \mathrm{l}$ (from $17.4 \%$ to $27.7 \%$ ) was observed. Thus, liraglutide allowed more patients to achieve an adequate control of cardiovascular risk factors and may result in reduced cardiovascular risk, although this hypothesis must be confirmed in prospective clinical trials which are currently ongoing.

In type $2 \mathrm{DM}$ patients previously treated with DPP-4 inhibitors, switching to liraglutide induced an improvement in $\mathrm{HbA}_{1 \mathrm{c}}$ and weight in line with previous real-life studies $[16,19]$. According to this, switching patients who are inadequately controlled with DPP-4 inhibitors to liraglutide is an effective strategy. There were no significant differences in weight or $\mathrm{HbA}_{1 \mathrm{c}}$ reduction in patients who remained on DPP4 inhibitors during liraglutide treatment, compared to patients who switched to liraglutide from DPP4 inhibitors. Violante and 


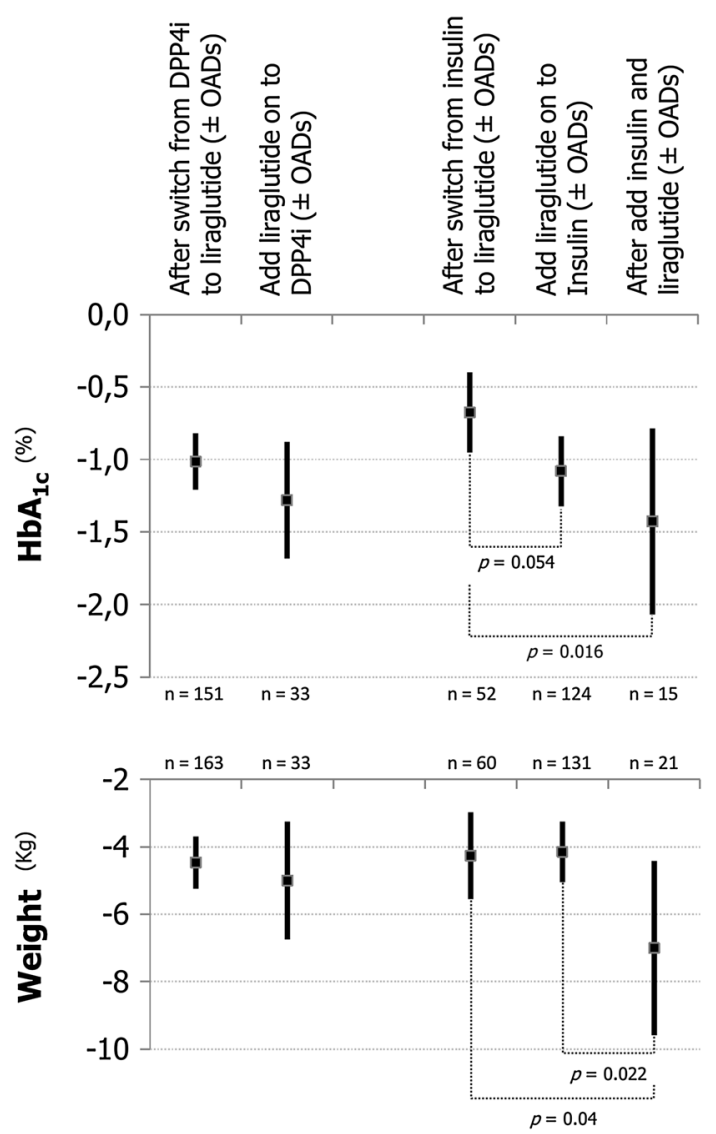

Fig. 5 Changes in $\mathrm{HbA}_{1 \mathrm{c}}$ and weight after liraglutide treatment according to DPP4 inhibitor and insulin treatment variations. Data are mean (point) and 95\% confidence interval. $H b A_{1 c}$ glycated hemoglobin, $O A D s$ oral antidiabetic drugs. $p$ values are shown for $t$ test

colleagues showed that the addition of exenatide twice daily to patients inadequately controlled with sitagliptin and metformin provided better glycemic control than switching to exenatide, although the longer half-life of liraglutide compared to exenatide may explain this discrepancy [20]. Moreover, when considering the additional efficacy observed after the combination of exenatide and sitagliptin $\left(\mathrm{HbA}_{1 \mathrm{c}}\right.$ reduction of $\left.-0.3 \%\right)$ and the cost of the treatment, it may be of limited utility.

$24.2 \%$ of patients treated with metformin, basal insulin and liraglutide reached a composite end point of $\mathrm{HbA}_{1 \mathrm{c}}<7 \%$ and reduction in weight without hypoglycemia. In the meta-analysis performed by Zinman and colleagues [21], the percentage of patients reaching this composite end point at 26 weeks was $15 \%$ for patients treated with glargine. The decrease in $\mathrm{HbA}_{1 \mathrm{c}}$ and weight was higher in patients for whom liraglutide was added to insulin \pm OADs and patients for whom liraglutide and insulin were added to previous treatment, compared to patients who switched from insulin \pm OADs to liraglutide \pm OADs. After the initiation of insulin, an increase in hypoglycaemic episodes and weight occurs [22], which may influence cardiovascular risk and is often a concern both for patients and physicians. Moreover, patients treated with insulin often do not achieve an adequate $\mathrm{HbA}_{1 \mathrm{c}}$ [23]. Thus, our data indicates the utility of liraglutide in insulin-treated patients.

Our study has several limitations. First, due to the observational design, study visits were not strictly specified and the time between liraglutide initiation and laboratory data was more flexible. Secondly, clinical events and adverse events may not have been fully reflected by the study. Besides, due to the retrospective design, only patients with at least two visits (before and after liraglutide treatment) were included in the study, and probably the majority of patients with intense gastrointestinal adverse events were discontinued on their last visit. This fact probably has influenced the low rate of gastrointestinal symptoms reported in the present study, which is lower than that in previous data. Moreover, if we consider that in many of the $10 \%$ of patients who did not complete the two visits, the reason may be due to secondary effects, the percentage is similar to previous data from observational studies. In addition, the absence of data from patients with early withdrawal from liraglutide treatment 
may result in better glycemic and weight results and also in less adverse events, compared to those that would take place in the whole population of liraglutide-treated patients. Finally, due to the heterogeneity of patient's characteristics, results from between group's comparisons should be interpreted with caution. On the other hand, the strength of our study is the size of the sample, which was larger than that of some of the previous observational studies. This may improve the reproducibility of the results when applying them to the general population.

\section{CONCLUSION}

Our study confirms the effectiveness of liraglutide in a real-world setting. In our cohort of patients with type $2 \mathrm{DM}$, treatment with liraglutide induced a significant reduction in $\mathrm{HbA}_{1 \mathrm{c}}$, weight, lipids and blood pressure. Our results confirm the benefits observed in clinical trials.

\section{ACKNOWLEDGMENTS}

This study was supported with funding from the Spanish Society of Endocrinology and Nutrition. All named authors meet the International Committee of Medical Journal Editors (ICMJE) criteria for authorship for this manuscript, take responsibility for the integrity of the work as a whole, and have given final approval for the version to be published. The final version of the manuscript has been revised and approved for the members of the Diabetes Mellitus Working Group and for members of the board of directors of the Spanish Society of Endocrinology and Nutrition.

Conflict of interest. P. Mezquita-Raya has participated as investigator in clinical studies sponsored by Amgen, Boeringher, Bristol-Myers Squibb, Janssen, Lilly, Roche, Sanofi Aventis, Novo Nordisk, Pfizer and Tolerx, and has received honoraria for clinically advising or as speaker from Astra-Zeneca, Bayer, Bristol-Myers Squibb, Faes, Janssen, Lifescan, MSD and Novo Nordisk. R. Reyes-Garcia has participated as investigator in clinical studies sponsored by Amgen, Boeringher, Janssen, Lilly, Novo Nordisk and Roche, and has received honoraria as speaker from Novo Nordisk, Sanofi Aventis, GSK, Faes, Almirall and Novartis. O. Moreno-Perez has participated as investigator in clinical studies sponsored by Sanofi Aventis and has received honoraria for clinically advising or as speaker from Novo Nordisk, Lilly, MSD, Boehringer, Janssen and Astra-Zeneca. M. Lopez de la Torre Casares has participated as investigator in clinical studies sponsored by Novo Nordisk, Lilly, Intarcia, Bristol-Myers Squibb, Sanofi Aventis, GSK and Novartis, and has received honoraria for clinically advising or as speaker from Novo Nordisk, Lilly, Novartis, Sanofi Aventis, MSD, Boehringer Ingelheim, Astra-Zeneca, BristolMyers Squibb, Esteve, Faes, Almirall, GSK and Ferrer. J. Escalada-San-Martín has participated as investigator in clinical studies sponsored by Abbott, Lilly and Novo Nordisk, and has received honoraria for clinically advising or as speaker from Almirall, Astra- Zeneca, Boehringer, Bristol-Myers Squibb, Esteve, Ferrer, Lilly, MSD, Novo Nordisk, and Sanofi Aventis. M. Rubio-Herrera has participated as investigator in clinical studies sponsored by Abbott, Bayer, Sanofi Aventis, Roche, MSD, Novo Nordisk, Nestlé Healthcare and Vegenat, and has received honoraria for clinically advising or as speaker from Abbott, Lilly, Novo Nordisk, Sanofi, GSK, Astra-Zeneca, Almirall, Bristol-Myers Squibb, MSD, Roche, Nestlé Healthcare, Nutricia and Vegenat. 
Compliance with ethics guidelines. The study was approved by the ethical review board of the centers which took part in the study, and it was done in compliance with the ethic guidelines for research in humans. All the procedures were in accordance with the ethical standards of the responsible committee on human experimentation (institutional and national) and with the Helsinki Declaration of 1964, as revised in 2013. All the participants in the study provided informed consent after a full explanation of the purpose of the study. Informed consent was obtained from all patients for being included in the study.

Open Access. This article is distributed under the terms of the Creative Commons Attribution Noncommercial License which permits any noncommercial use, distribution, and reproduction in any medium, provided the original author(s) and the source are credited.

\section{REFERENCES}

1. Mezquita Raya P, Reyes García R. Is treatment with liraglutide efficient? Endocrinol Nutr. 2014;61:202-8.

2. AACE/ACE Comprehensive Diabetes Management Algorithm. https://www.aace.com/files/aace_ algorithm.pdf. Accessed Apr 10, 2015.

3. Inzucchi SE, Bergenstal RM, Buse JB, Diamant M, Ferrannini E, Nauck M, American Diabetes Association (ADA); European Association for the Study of Diabetes (EASD), et al. Management of hyperglycemia in type 2 diabetes, 2015: a patientcentered approach: update to a position statement of the American Diabetes Association and the European Association for the Study of Diabetes. Diabetes Care. 2015;38:140-9.

4. Reyes García R, Mezquita Raya P. How to prevent and treat pharmacological hypoglycaemias. Rev Clin Esp. 2014;214:202-8.

5. Mezquita-Raya P, Reyes-García R, Moreno-Pérez Ó, Muñoz-Torres M, Merino-Torres JF, GorgojoMartínez JJ, et al. Position statement: hypoglycaemia management in patients with diabetes mellitus. Diabetes Mellitus Working Group of the Spanish Society of Endocrinology and Nutrition. Endocrinol Nutr. 2013;60:517.e1-18.

6. Marre M, Shaw J, Brändle M, Bebakar WM, Kamaruddin NA, Strand J, LEAD-1 SU Study Group, et al. Liraglutide, a once-daily human GLP1 analogue, added to a sulphonylurea over 26 weeks produces greater improvements in glycaemic and weight control compared with adding rosiglitazone or placebo in subjects with Type 2 diabetes (LEAD-1 SU). Diabet Med. 2009;26:268-78.

7. Nauck M, Frid A, Hermansen K, Shah NS, Tankova $\mathrm{T}$, Mitha $\mathrm{IH}$, et al. Effectiveness and safety comparison of liraglutide, glimepiride, and placebo, all in combination with metformin in type 2 diabetes mellitus (LEAD-2 Met). Diabetes Care. 2009;32:84-90.

8. Garber A, Henry R, Ratner R, Garcia-Hernandez PA, Rodriguez-Pattzi $\mathrm{H}$, Olvera-Alvarez $\mathrm{I}$, et al. Liraglutide versus glimepiride monotherapy for type 2 diabetes(LEAD-3 mono): randomised, 52-week, phase III, double-blind, paralleltreatment trial. Lancet. 2009;373:473-81.

9. Zinman B, Gerich J, Buse JB, Lewin A, Schwartz S, Raskin $\mathrm{P}$, et al. LEAD-4 Study Investigators. Effectiveness and safety of the human glucagonlike peptide-1 analog liraglutide in combination with metformin and thiazolidinedione in patients with type 2 diabetes (LEAD-4 Met + TZD). Diabetes Care. 2009;32:1224-30.

10. Russell-Jones D, Vaag A, Schmitz O, Sethi BK, Lalic $\mathrm{N}$, Antic S, et al. Liraglutide Effect and Action in Diabetes 5 (LEAD-5) met + SU Study Group. Liraglutide vs insulin glargine and placebo in combination with metformin and sulfonylurea therapy in type 2 diabetes mellitus (LEAD-5 met $+\mathrm{SU}):$ a randomised controlled trial. Diabetologia. 2009;52:2046-55.

11. Rigato M, Fadini GP. Comparative effectiveness of liraglutide in the treatment of type 2 diabetes. Diabetes Metab Syndr Obes. 2014;7:107-20.

12. Mezquita Raya P, Pérez A, Ramírez de Arellano A, Briones T, Hunt B, Valentine WJ. Incretin therapy for type 2 diabetes in Spain: a cost-effectiveness analysis of liraglutide versus sitagliptin. Diabetes Ther. 2013;4:417-30.

13. Evans M, McEwan P, O'Shea R, George L. A retrospective, case-note survey of type 2 diabetes patients prescribed incretin-based therapies in clinical practice. Diabetes Ther. 2013;4:27-40.

14. Fadini GP, Simioni N, Frison V, Dal Pos M, Bettio M, Rocchini $\mathrm{P}$, et al. Independent glucose and weight 
reducing effects of Liraglutide in a real-world population of type 2 diabetic outpatients. Acta Diabetol. 2013;50:943-9.

15. Mulligan CM, Harper R, Harding J, Mcllwaine W, Petruckevitch A, McLaughlin DM. A retrospective audit of type 2 diabetes patients prescribed liraglutide in real-life clinical practice. Diabetes Ther. 2013;4:147-51.

16. Heymann A, Maor Y, Goldstein I, Todorova L, Schertz-Sternberg P, Karasik A. Efficacy of liraglutide in a real-life cohort. Diabetes Ther. 2014;5:193-206.

17. Chitnis AS, Ganz ML, Benjamin N, Langer J, Hammer M. Clinical effectiveness of liraglutide across body mass index in patients with type 2 diabetes in the United States: a retrospective cohort study. Adv Ther. 2014;31:986-99.

18. Garber A, Henry RR, Ratner R, Hale P, Chang CT, Bode B, LEAD-3 (Mono) Study Group. Liraglutide, a once-daily human glucagon-like peptide 1 analogue, provides sustained improvements in glycaemic control and weight for 2 years as monotherapy compared with glimepiride in patients with type 2 diabetes. Diabetes Obes Metab. 2011;13:348-56.

19. Charpentier G, Martinez L, Eschwège E, Madani S, Penfornis A, Gourdy P, et al. Effectiveness of the human GLP-1 analogue liraglutide in patients with type 2 diabetes who switched from a DPP-4 inhibitor: 1-year data from the EVIDENCE study. Diabetologia. 2013;56(Suppl 1):S358.

20. Violante R, Oliveira JH, Yoon $\mathrm{KH}$, Reed VA, Yu MB, Bachmann OP, et al. A randomized non-inferiority study comparing the addition of exenatide twice daily to sitagliptin or switching from sitagliptin to exenatide twice daily in patients with type 2 diabetes experiencing inadequate glycaemic control on metformin and sitagliptin. Diabet Med. 2012;29:e417-24.

21. Zinman B, Schmidt WE, Moses A, Lund N, Gough S. Achieving a clinically relevant composite outcome of an HbA1c of $<7 \%$ without weight gain or hypoglycaemia in type 2 diabetes: a meta-analysis of the liraglutide clinical trial programme. Diabetes Obes Metab. 2012;14:77-82.

22. Jansen HJ, Vervoort GM, de Haan AF, Netten PM, de Grauw WJ, Tack CJ. Diabetes-related distress, insulin dose, and age contribute to insulinassociated weight gain in patients with type 2 diabetes: results of a prospective study. Diabetes Care. 2014;37:2710-7.

23. Pérez A, Mediavilla JJ, Miñambres I, GonzálezSegura D. Glycemic control in patients with type 2 diabetes mellitus in Spain. Rev Clin Esp. 2014;214:429-36. 